\title{
ORIENTAÇÃO ÉTICA
}

\section{QUANTO A MUDANÇA}

\section{SOCIAL ENVOLVENDO}

\section{STAKEHOLDERS}

MAR\|A LUISA MENDES TE\|XE\|RA

Professora da Universidade Presbiteriana Mackenzie

JOSÉ AFONSO MAZZON

Professor da Universidade de São Paulo 


\section{$1 \quad$ I NTRODU ÇÃO}

A competitividade turbulenta, estimulada por um cenário tecnológico que acelera a velocidade da internacionalização da economia e a mudança de valores sociais - estes tendendo à valorização da ética e do respeito ao indivíduo -, exige das organizações a revisão das suas responsabilidades e estratégias (Lazer et al., I990; McKenna, I991; Badot e Cova, I992; Clancy e Shulman, I993; Popcorn, I993), bem como encaminhamento de novas formas de ação externas e internas (Achrol, I99I).

Para Badot \& Cova (I992), a empresa é um ator social e não apenas um ator econômico limitado ao ambiente de mercado, já que à introdução de novos produtos estão associados novos valores que devem fazer sentido no projeto de vida do consumidor. Introduzir sentidos e valores na sociedade, como propõem McKenna (I99I) e Badot \& Cova (I992), implica uma mudança planejada de valores, que pode estar associada a outras mudanças sociais, devendo fazer sentido na vida da sociedade, dos clientes, dos empregados, orientadas por uma inserção ética da organização na sociedade, num dado tempo e espaço.

Em uma época em que as arenas da competição se redesenham, ultrapassando fronteiras geográficas, conhecer os valores e atitudes dos executivos quanto à orientação ética de processos de mudanças torna-se especialmente relevante, ao ser necessário desenvolver mercados em realidades multilocais, culturais e sociais pouco conhecidas, como é o caso da América Latina.

\section{REFERENCIAL TEÓRICO}

Os processos de mudança que envolvam o comportamento de pessoas podem ser considerados como mudança social ao ser esta entendida como "o processo através do qual alterações ocorrem na estrutura ou funcionamento de uma unidade do sistema social", que se caracteriza pela interação ou "troca social" - "processo através do qual duas ou mais partes suprem uma à outra de 
benefícios (ou penalidades) para mútuo ganho ou perda" - constituindo-se no "mecanismo nuclear da vida social" e tendo por principal função a regulagem do comportamento, por um lado, e, por outro, gerando tensão para a mudança (Levy e Zaltman, I975:5I).

A mudança social é um fenômeno coletivo que afeta as condições de vida de seus componentes, que atuam no sentido de originar, acentuar, diminuir ou impedir as modificações de partes ou da totalidade da organização social.

As organizações estão inseridas num contexto social que envolve diversos stakeholders, estes entendidos como "grupos ou indivíduos com os quais a organização interage ou possui interdependência", ou ainda, "qualquer indivíduo ou grupo que pode afetar ou ser afetado por ações, decisões, políticas, práticas ou objetivos alcançados pela organização" (Carrol, I993).

As tradicionais teorias da organização indicam que a principal função das empresas consiste em maximizar o retorno sobre investimento dos proprietários do negócio (Friedman, I970). Em contraste, a teoria dos stakeholders propõe que as empresas precisam considerar os interesses dos grupos por ela afetados (Gibson, 2000).

Os grupos com os quais as empresas interagem podem ser classificados em primários, aqueles com os quais são estabelecidas relações contratuais, sendo os demais denominados secundários (Carrol, I993). Segundo Gibson (2000), os gerentes devem considerar, na gestão dos negócios, os interesses dos grupos secundários e não apenas os dos primários, desde que tenham potencial de interferir de forma significativa na vida desses negócios.

As organizações interferem nas realidades sociais em que se inserem, devendo assumir responsabilidades, quer participando ativamente da reconstrução ética da sociedade (Popcorn, I993), contribuindo para uma melhor qualidade de vida (Drucker, I993), introduzindo novos valores e sentidos (Badot \& Cova, I992), quer em relação a estratégias de mercado (McKenna, I99I; Lazer et al., r990).

A mudança social pode ser planejada por parte de um agente na medida em que ocorra uma intervenção, com o objetivo consciente de promover uma alteração na magnitude e direção de um determinado comportamento social ou de consumo (Niehoff, I966; Lippitt Watson \& Westley, I968; Jones, I969; Horntein et al., I97I; Zaltman \& Duncan I977).

Ao intervir numa realidade social, promovendo mudanças de comportamento, o agente se vê, ainda que não-conscientemente, envolvido numa questão ética.

Entre as abordagens éticas na condução dos negócios, Allinson (I998) destaca: a deontológica, a qual pode ser definida como a versão do ponto de vista do que é considerado certo ou errado, independentemente das consequências; a 
utitlitária, que enfatiza os benefícios sociais que uma ação pode produzir; e a egoística, que consiste essencialmente em perseguir o interesse próprio.

O comportamento dos gestores é influenciado por seus valores, quando estes se transformam em crenças duradouras, os quais, organizados entre si, orientam a resolução de conflitos, julgamentos e tomada de decisão. Constituem-se em componentes cognitivos nucleares que orientam as atitudes defendidas pelas pessoas, bem como os incontáveis comportamentos sociais relevantes que engajam. Podem ser classificados em valores terminais e instrumentais. Os primeiros referem-se a formas desejadas de vida; os segundos, a formas desejadas de conduta, estas destinadas à realização daquelas (Rokeach, I973).

Vinson, Scott \& Lamont (I977) identificaram a existência de relacionamento entre valores terminais, valores de domínio específico e crenças avaliativas. Os valores de domínio específico refletem a crença que as pessoas adquirem por meio da experiência em situações específicas ou domínios de atividade; e as crenças descritivas e avaliativas são identificadoras de atitudes.

Tomando-se como referencial os achados de Vinson, Scott \& Lamont (I977), pode-se dizer que aos valores terminais dos gestores associam-se valores de domínio específico relativos à vivência da gestão de empresas, e crenças avaliativas (atitudes) quanto à orientação ética do gerenciamento das relações com os stakeholders, com os quais as organizações interagem em processos que envolvem mudanças de seus comportamentos.

A noção de que os valores influem no comportamento dos indivíduos e nas organizações data de algumas décadas; pesquisadores das mais diversas especialidades de gestão têm discutido a importância que os valores desempenham na organização (Agle \& Caldwell, I999).

Ao realizar suas atividades, as organizações, promovem mudanças na sociedade, envolvendo os seus stakeholders primários e secundários, sofrendo, em suas ações, a influência dos valores de seus gestores.

\section{PROBLEMA E METODOLOGIA DE PESQUISA}

Tendo como critério os valores terminais na concepção de Rokeach (I973) e a afirmação de Kamakura \& Mazzon (I99I) quanto à tendência atual de utilizar valores para efeito de segmentação, Teixeira (I995) pesquisou executivos, identificando quatro perfis: o "Controlador", defensor de valores como "Paz Mundial" e "Segurança Nacional", que apresenta baixa capacidade de aceitar diferenças e resolver conflitos; o "Maduro Flexível", que valoriza principalmente "Liberdade" e a "Auto-Realização", tende a respeitar a liberdade própria e a alheia, a investir 
na auto-realização própria e na de outros, que possui disponibilidade para aceitar diferenças e resolver conflitos pela negociação; o "Religioso", tendendo a valorizar mais a "salvação" e a "segurança familiar", orienta-se para o enfoque micro da realidade e procura proteger-se quanto ao próprio bem-estar; o "Aberto Aparente" é o mais centrado em si mesmo, valorizando, além do "conforto", aspectos contraditórios como "vida excitante" e "segurança familiar"; administra conflitos admitindo aparentemente as diferenças e com disposição para negociação, mas procura livrar-se de tudo o que o incomoda.

As reflexões sobre a questão ética de promoção da mudança social envolvendo stakeholders, o fato das ações serem orientadas pelos valores e os tipos de executivos encontrados por Teixeira (I995), conduziram à seguinte questão-problema:

A orientação ética para promover mudanças sociais envolvendo stakeholders está associada aos perfis de valores terminais dos executivos "Controlador", "Maduro Flexível", "Religioso" e "Aberto Aparente"?

Consideraram-se como stakeholders, para efeito desta pesquisa, os empregados e clientes - stakeholders primários - e a sociedade - stakeholders secundários.

Por ser de natureza descritiva, à qual se adequa o método quantitativo (Evrard, I993), envolvendo variáveis de caráter interveniente, optou-se pelo método de estudo de campo, mediante levantamento e análise de dados fornecidos pelos respondentes em questionário fechado, com frases associadas a escalas múltiplas do tipo Likert, aconselhadas para medir atitudes (Parasuraman, I99I).

A validade de conteúdo foi alcançada submetendo-se o questionário à apreciação de executivos da população. A validade do constructo foi avaliada por análise fatorial, de modo a reduzir a redundância entre as variáveis. Quanto à confiabilidade, as escalas do tipo Likert, por possuirem um número pequeno de pontos, há dificuldade em obtê-la no que se refere a fazer predições em relação às respostas dos indivíduos, mas servem para diferenciar atitudes entre grupos, o que atendeu aos objetivos da pesquisa.

A população pesquisada constituiu-se de presidentes, diretores e gerentes das áreas de marketing/comercial, produção/industrial, financeira/administrativa, de recursos humanos, de indústrias privadas com 200 ou mais empregados, situadas no Estado do Rio de Janeiro, de onde foi extraída uma amostra não probalística de 224 executivos pertencentes a iı2 empresas.

Utilizaram-se, para tratamento de dados, técnicas univariadas e multivariadas, tais como: análise fatorial, com o objetivo de avaliar a estrutura de intercorrelações existentes num amplo conjunto de variáveis, de modo a reduzir esse conjunto a uma dimensão menor, sem perda significativa de informação e, ao 
mesmo tempo, identificar fatores subjacentes ao, comportamento, dos executivos; e correspondência mediante construção de mapeamentos perceptuais, evidenciando a associação existente entre as variáveis relativas à ação das empresas na mudança social envolvendo stakeholders e os segmentos identificados por Teixeira (I995).

O estudo da existência desta associação, procurando identificar se a mesma se verifica, ou não, pode ser particularmente útil ao fornecer subsídios que podem vir a contribuir para a compreensão das ações das empresas na promoção de mudanças sociais que visam ao incremento da competitividade, considerando, porém, como equilíbrio dos interesses os stakeholders.

\section{RESULTADOS DA PESQUISA}

\section{1 CARACTERIZAÇÃO DEMOGRÁFICA DA AMOSTRA}

Os executivos pesquisados pertencem, em sua maioria, ao sexo masculino, possuem nível de instrução superior $(6 \mathrm{I}, 6 \%)$, têm idade entre 30 e 50 anos $(79,0 \%)$, são de nacionalidade brasileira $(93,8 \%)$, descendentes de pais brasileiros $(8 \mathrm{I}, 7 \%)$, naturais do Rio de Janeiro $(67, \mathrm{I} \%)$; ocupam posições de gerência e diretoria $(89,7 \%)$, sendo das áreas de produção/industrial $(32,1 \%)$, comercial/marketing $(28, \mathrm{I} \%)$ e recursos humanos $(27,7 \%)$, estando subordinados à diretoria $(42,0 \%)$ e presidência $(34,8 \%)$

\section{2 PERFIS DOS EXECUTIVOS QUANTO À ORIENTAÇÃO ÉTICA PARA A MUDANÇA SOCIAL ENVOLVENDO STAKEHOLDERS}

Para oferecer um panorama dos grupos de executivos comparados entre si e adquirir maior sensibilidade de interpretação, recorreu-se à análise descritiva da diferença percentual das médias obtidas dos segmentos em cada variável com relação à média da amostra e à elaboração do mapa perceptual mediante análise de correspondências.

Quer para a análise descritiva quer para a elaboração do mapa perceptual, adotou-se a seguinte notação das variáveis:

\subsubsection{Análise Descritiva}

A análise descritiva revelou os seguintes aspectos destacáveis: 
ACEC Uma ação pode-se dizer eticamente correta quanto está de acordo com uma série de princípios aprovados por instituições sociais, como religião, por exemplo, responsáveis pela orientação da sociedade.

ALTV A empresa deve investir esforços para alterar valores e comportamentos de seus clientes, tendo em vista os objetivos que ela pretende alcançar.

ETCU Na prática, a ética depende dos interesses de cada um.

INCS Os interesses da empresa devem estar acima dos interesses dos clientes e da sociedade.

INMS A empresa, tendo em vista seus interesses, deve investir na mudança de valores e comportamentos da sociedade para que possa realizá-los.

INVM A empresa deve investir na mudança de valores e comportamentos do mercado, tendo em vista os objetivos que ela pretende alcançar.

MVLC Antes de introduzir um produto ou serviço no mercado, a empresa deve identificar qual a mudança de valores e comportamentos a eles associados, assumindo o papel de mudá-los.

ORET Desde que uma ação beneficie à maioria dos indivíduos por ela atingidos, pode-se dizer que está orientada eticamente.

SETC A empresa deve assumir a responsabilidade de transformar a sociedade, tornando-a mais ética.

VLCE A empresa deve investir esforços para alterar valores e comportamentos de seus empregados, tendo em vista os objetivos que ela pretende alcançar.

- O segmento Si, “Controlador”, apresentou a maior discordância quanto a transformar a sociedade, tornando-a mais ética.

- O segmento S2, "Maduro Flexível”, e o segmento S3, "Religioso" apresentaram a maior concordância quanto a alterar valores dos clientes; o primeiro mostrou a maior discordância quanto à afirmação de que a ética dependa dos interesses de cada um.

- O segmento $\mathrm{S}_{3}$, "Religioso", apresenta a maior discordância quanto à afirmação de que uma ação é ética desde que beneficie à maioria; mostra a maior concordância quanto a que esta possa ser desta forma considerada, desde que atenda a princípios religiosos.

- O segmento $\mathrm{S}_{4}$, “Aberto Aparente”, apresenta a maior discordância quanto a alterar valores de clientes e a maior concordância quanto à ética depender dos interesses de cada um.

\subsubsection{Análise do Mapa Perceptual}

A análise dos resultados obtidos permite destacar como pontos relevantes:

- Os dois primeiros eixos extraídos explicam 96,4\% da variância dos dados, sendo $78,0 \%$ no eixo horizontal e $18,4 \%$ no eixo vertical. Os resultados esta- 
tísticos evidenciam que a expressiva maioria das variáveis tem suas contribuições fundamentalmente associadas com esses dois primeiros eixos.

- Os segmentos que têm percepções mais contrapostas entre si são (Quadro I): O segmento SI "Controlador" versus o segmento $\mathrm{S}_{3}$ "Religioso".

O segmento S2 "Maduro Flexível” versus o segmento S4 "Aberto Aparente".

\subsubsection{Síntese da Orientação Ética dos Perfis para} a Mudança Social Envolvendo Stakeholders

Tendo em vista a análise descritiva e a análise do mapa perceptual, chegouse aos seguintes perfis dos grupos de executivos quanto à orientação para a mudança:

\subsubsection{Segmento SI - "Controlador"}

Este segmento orienta-se por uma ética utilitarista ao considerar que uma ação que beneficia a maioria das pessoas envolvidas pode ser considerada como eticamente correta e por mostrar-se desfavorável a que as ações devam basearse em princípios religiosos, característicos de uma ética deontológica.

O fato de ter-se mostrado favorável a que os interesses estejam acima dos clientes e da sociedade, bem como por não se ter mostrado favorável quanto à transformação desta sociedade, tornando-a mais ética e, por ser o seu estilo controlador, agindo orientado para o controle do meio que o envolve, faz supor que a consideração de que a ética deve basear-se no benefício da maioria refira-se realmente a uma maioria, cujos interesses estão em jogo, defendendo-os sem considerar os interesses dos stakeholders, com quem interage.

\subsubsection{Segmento S2 - "Maduro Flexível"}

Este segmento apresenta uma certa indefinição quanto à postura ética ao posicionar-se desfavoravelmente a que esta varie de acordo com os interesses de cada um, bem como por ter-se mostrado desfavorável a que esta se baseie no benefício da maioria, sem, todavia, ter-se apresentado francamente favorável a orientar-se por princípios aprovados por instituições sociais, como os "Religiosos". Pode ocorrer que este segmento tenha uma orientação deontológica, porém, baseada em alguma outra classe de princípios não captados nesta pesquisa.

O segmento "Maduro Flexível" mostra-se mais favorável a mudanças. Entendem que a empresa deve investir esforços na mudança de valores e comportamentos de empregados, clientes e mercado, de acordo com os objetivos que pretende alcançar. Mostram-se desfavoráveis a mudanças na sociedade. Isto sugere que o seu interesse em investir em mudanças, com vistas ao alcance de 


\section{QUADRO I}

\begin{tabular}{|c|c|c|}
\hline \multicolumn{3}{|c|}{ ORIENTAÇÃO PARA MUDANÇA: CONTRAPOSIÇÂOO ENTRE SEGMENTOS } \\
\hline POSIÇÃO & SEGMENTO S1 - "CONTROLADOR" & SEGMENTO S3 - "RELIGIOSO" \\
\hline Favorável & $\begin{array}{l}\text { os interesses da empresa acima de } \\
\text { clientes e sociedade } \\
\text { - ética baseada no benefício } \\
\text { da maioria } \\
\text { - mudança de valores e comportamen- } \\
\text { tos de empregados e mercado }\end{array}$ & $\begin{array}{l}\text { - ética com base na religião } \\
\text { mudança de valores e comporta- } \\
\text { mentos associados a novos produ- } \\
\text { tos e mercado. }\end{array}$ \\
\hline \multirow[t]{2}{*}{ Desfavorável } & $\begin{array}{l}\text { - ética baseada na religião } \\
\text { mudança de valores e comporta- } \\
\text { mentos associados a novos produ- } \\
\text { tos e mercado }\end{array}$ & $\begin{array}{l}\text { - ética baseada no benefício da } \\
\text { maioria } \\
\text { - interesses da empresa acima de } \\
\text { clientes e sociedade } \\
\text { - mudança de valores e comportamen- } \\
\text { tos de empregados e mercado }\end{array}$ \\
\hline & SEGM ENTO S2 - "ABERTO FLEXÍVEL" & SEGMENTO S4 - "ABERTO APARENTE" \\
\hline Favorável & $\begin{array}{l}\text { mudanças de valores e comporta- } \\
\text { mentos de clientes, empregados e } \\
\text { mercado }\end{array}$ & $\begin{array}{l}\text { - na prática, a ética depende dos } \\
\text { interesses de cada um } \\
\text { - mudança de valores e comporta- } \\
\text { mentos da sociedade } \\
\text { - ética baseada no benefício da } \\
\text { maioria } \\
\text { - transformar a sociedade, tornando- } \\
\text { a mais ética }\end{array}$ \\
\hline Desfavorável & $\begin{array}{l}\text { - na prática, a ética depende dos } \\
\text { interesses de cada um } \\
\text { - mudança de valores e comporta- } \\
\text { mentos da sociedade } \\
\text { - ética baseada no benefício da } \\
\text { maioria } \\
\text { - transformar a sociedade, tornando-a } \\
\text { mais ética }\end{array}$ & $\begin{array}{l}\text { mudanças de valores e comporta- } \\
\text { mentos de clientes, empregados e } \\
\text { mercado }\end{array}$ \\
\hline
\end{tabular}

objetivos de desempenho da empresa, está num raio que abrange até o horizonte do mercado, não chegando propriamente a alcançar a sociedade como um todo.

\subsubsection{Segmento S3 - "Religioso"}

Regido pelo valor "salvação", este segmento entende que uma ação pode dizer-se ética quando está orientada por princípios institucionais, como a Reli- 
gião, não aceitando que os interesses da empresa estejam acima dos interesses dos clientes e nem da sociedade. Posiciona-se contrário à ética baseada no benefício da maioria. Um aspecto chama a atenção: talvez fosse de se esperar um posicionamento fortemente desfavorável à idéia de que a ética, na prática, depende dos interesses de cada um. No entanto, tal não ocorreu, tendo este segmento apresentado até mesmo alguma correlação positiva, sugerindo que o comportamento ético talvez não seja tão rigoroso, como poderia à primeira vista parecer. Não demonstrou, também, interesse em investir em mudanças na sociedade, visando torná-la mais ética.

Embora seja um segmento religioso, não se mostrou muito interessado em fazer mudanças, tornando a sociedade mais ética, embora não concorde que os interesses da empresa devam estar acima dos interesses sociais.

\subsubsection{Segmento S4 - "Aberto Aparente"}

Este segmento, apesar de ter-se mostrado favorável a que a empresa assuma a responsabilidade de tornar a sociedade mais ética, é o que mais assume que a ética depende dos interesses de cada um e que uma ação, se beneficia à maioria dos indivíduos, pode-se dizer que está eticamente correta. Indica pautar-se, em suas ações, em uma ética utilitarista e egoística.

A incoerência entre a orientação ética e a favorabilidade a transformar a sociedade, tornando-a mais ética, sugere uma contradição entre discurso e ação, ou, então, a intenção de tornar a sociedade mais "ética" de acordo com interesses próprios e egoísticos.

\section{CONCLUSÕES E SUGESTÕES}

Os resultados da pesquisa permitiram identificar que a orientação ética para a mudança social envolvendo stakeholders está associada aos valores globais que constituem os perfis encontrados por Teixeira (I995).

Em relação ao papel da empresa junto à sociedade, o segmento "Aberto Aparente" é o único que se coloca mais favoravelmente ao investimento na mudança social para torná-la mais ética; porém, é também o que mais defende a idéia de que a ética varia de acordo com os interesses de cada um, o que permite questionar o seu posicionamento. Em contrapartida, o segmento "Maduro Flexível", embora se posicionando desfavoravelmente ao investimento na mudança ética da sociedade, é o único que se mostra efetivamente desfavorável à idéia que a ética varie de acordo com os interesses individuais.

O segmento S3 - "Religioso" - pouco favorável a mudanças, revela-se um 
pouco mais disponível para efetuá-las quando as mesmas dizem respeito a clientes, no momento em que se procura introduzir novos produtos. O segmento SI - "Controlador" - mostra-se o menos favorável a qualquer tipo de mudança.

Esses resultados evidenciam que os executivos mostram-se, em sua maioria, com alguma sensibilidade quanto a investimentos em mudanças pertinentes aos valores e comportamentos do mercado, porém, sem uma posição ética clara.

Em vista destes resultados, pode-se concluir que a preocupação com o papel da empresa, tornando a sociedade mais ética, situa-se preponderantemente na esfera do discurso. Isto é algo que preocupa, especialmente se a responsabilidade das empresas for vista com os olhos de Popcorn (I993), que percebe a sociedade exigindo mais do que a simples oferta de bens e serviços que atendam aos anseios dos consumidores, chamando tais empresas a participar ativamente na transformação ética da sociedade.

Tem-se a impressão de que os executivos pesquisados vêem a alteração de comportamentos do mercado e da sociedade como uma ação em defesa de seus interesses e aqueles das empresas que dirigem. Têm o intuito de impor-se e menos direcionar-se na busca de nichos e, dentro destes, atender aos interesses das organizações, envolvendo uma parceria constante com a sociedade, mercado, clientes e empregados. Este aspecto desperta cuidado e atenção por parte de empresas e países, uma vez que essas empresas operam em locais e culturas diversos e em uma economia internacionalizada.

Nota-se que, entre os executivos pesquisados, há uma tendência para a defesa de uma ética utilitarista e até egoística, em que se defende os interesses da empresa acima daqueles dos stakeholders, em vez de um equilíbrio entre os interesses de todos, como a teoria propõe.

Em uma época em que se defende uma vida mais equilibrada para a sobrevivência saudável da humanidade, os resultados permitem concluir que há necessidade de investir no desenvolvimento de posturas éticas dos executivos, diferentes da utilitarista e egoística, especialmente tendo em vista a tendência das empresas de atuarem em diversas culturas, numa economia globalizada.

Além disso, é preciso tomar especial cuidado com a seleção e transferência de executivos de uma país para o outro, de forma a que os consumidorescidadãos possam ser respeitados e a empresa agregue valor ao orientar-se por esse respeito. 


\section{REFERÊ NCIAS BIBLIOGRÁFICAS}

ACHROL, Ravi S. Evolution of the Marketing Organizations: New Forms for Turbulent Environments. Journal of Marketing, v.55, p.77-93, oct. I991.

AGLE, Bradlley R., CALDWELL, Craig B. Understanding Research on Vallues in Business. Business and Society, Chicago, sep. I999.

ALLINSON, Robert. Ethical Values as a Part of the Definition of Business Enterprise and Part of Internal Structure of the Business Organization. Journal of Business Ethics, jul. I998.

BADOT, Olivier COVA, Bernard. Des Marketing en Mouvement, Vers un Néo-Marketing. Revue Française du Marketing, n.136, jan. I992.

CARROL, A. Business and Society: Ethics and Stakeholder Management. Cincinnati: SouthWestern Publishing, I993.

CIULLA, Joanne B. Why Is Business Talking About Ethics? Reflections on Foreign Conversations. California Management Review, v.34, n.I, p.67-86, fall i991.

CLANCY, Kevin, SHULMAN, Roberts. A Revolução no Marketing. Rio de Janeiro: LTC Livros Técnicos e Científicos, I993.

DRUCKER, Peter F. The Post-Capitalist Executive: An Interview with Peter F. Drucker. Harvard Business Review, p.II5-122, may/jun., I993.

ENGLAND, Georg. Personal Values Systems of American Managers. Academy of Management, mar., I967.

EVRARD, Yves et al. Market Études et Recherches en Marketing. [s. 1.]: Editions Nathan, I993.

FISCHER, Rosa Maria. A Política e as Políticas das Relaçôes de Trabalho. São Paulo, I983. Tese (Doutoramento), FFLCH/USP.

FRIEDMAN, Milton. The Social Responsability of Business is to Increase its Profits. New York Times, sept. I970.

GALAMBAUD, Bernard. Le Marketing Social or les Pieges de l'Analogie Métaphorique. Revue Française du Marketing, n.120, p.47-50, I988/5.

GIBSON, Kevin. The Moral Basis of Stakeholder Theory. Journal of Business Ethics. Dorcrecht, aug. 2000.

HOLMQUIST, Donna. Ethics - How Important is it in Today's Office? Public Personnel Management, v.22, n.4, p.537-544, winter, I993.

HORNTEIN, Harvey A. et al. Social Intervention: A Behavioral Approach. New York: Free Press, I97I.

JONES, Garth N. Planned Organizational Change. New York: Praeger, I969.

KAMAKURA, W. A., MAZZON, José Afonso. Value Segmentation: A Model for the Measurement of Values and Value Systems. Journal of Consumer Research, v.I8, sept. I99I.

KAWAKATSU, M., LARRECHÉ, J., VULPIAN. L'environnement et les Enterprises du Future. Table Ronde Prospective Animeé par Jacques Lesourne. Revue Française du Marketing, n.III, p.33-45, I987/I. 
KOTLER, P., ROBERTO, E. Marketing Social: Estratégias para Alterar o Comportamento Público. Rio de Janeiro: Campus, I992.

KOTLER, Philip, LEVY, Sidney, J. Broadning de Concept of Marketing. Journal of Marketing, p.Io-I5, jan. I969.

KOTLER, Philip, ROBERTO, E. Maarketing Social. Rio de Janeiro: Campus, I992.

LAZER, William et al. Marketing 2000 and Beyond American Marketing Association. Chicago: Americam Marketing Association, I990.

LEVY, Sidney, ZALTMAN, Gerald. Marketing Society and Conflict. New Jersey: Prentice Hall, I975.

LIPPITT, R. et al. The Dynamics of Planned Change. New York: Harcourt, I968.

McKENNA. Relationship Marketing. [s. 1.]: Addison-Wesley Publishing Company, I99I.

MICALEFF. A. Theorie du Marketing. In: JOFFRE P., SIMON Y. (Ed.). Encyclopédie de Gestion. Paris: Econômica, I989.

MURPHY, Patrick, LACZNIACK, R. Gene. Marketing Ethics: A Review with Implications for Managers, Educators and Researchers. Review of Marketing, p.25I-266, I98I.

NIEHOFF, Arthur. A Casebook of Social Change. Chicago: Aldine-Atherton, ig66.

PINE II, Joseph et al. Making Mass Costumization Work. Harvard Business Review, sep./oct. I993.

PARASURAMAN, A. Marketing Research. 2ed. [s. 1.]: Adisson-Wesley Publishing Company, I99I.

POPCORN, Faith. O Relatório Popcorn. Rio de Janeiro: Campus, I993.

POSNER, Bary Z., SCHMIDT, Warren H. Values and the Americam Manager: An update Updated. California Management Review, v.34, n.3, p.80-94, spring I992.

RAPP, Stau, COLLINS, John. Maximarketing: Os vencedores. São Paulo: Makron, I994.

ROKEACH, Miton. The Nature of Values. New York: The Free Press, I973.

SCHEIN, E. H. Coming to a New Awareness of Organizational Culture. Sloan Management Review, v.I2, p.3-16, winter I984.

TAGIURI, R. The Concept of Organizational Climate. In: LIKERT, R. The Human Organization. New York: McGraw-Hill Book, I965.

TAYLOR, Paul, W. Principles of Ethics: An Introduction. Encino, CA: Dickenson Publishing Company, Inc., I975.

TEIXEIRA, Maria Luisa M. Orientação para Marketing Social: Um Estudo de Valores e Atitudes dos Executivos. São Paulo, I995. Tese (Doutoramento). FEA/USP.

VINSON, Donald E., SCOTT, J., LAMONT, Laurence M. The Role of Personal Values in Marketing and Consumer Behavior. Journal of Marketing, p.44-50, apr. I977.

ZALTMAN, Gerald, DUNCAN, Robert. Strategies for Planned Social Change. New York: Willey Interscience, I977.

ZALTMAN, Gerald, STIFF, Ronald. Theories of Diffusion. In: WARDS, S., ROBERTSON, I. (Ed.). Consumer Behavior. Theoretical Sources. New Jersey: Prentice-Hall, I973.

ZALTMAN, Gerald. Strategies for Diffusing Innovations. In: SHETH, J. N., WRIGHT, Peter (Ed.). Marketing Analysis for Societal Problems. Urbana: University of Illinois Press, I974. 
WATSON, G. Social Psychology. Issues and Insights. Philadelphia: Lippincott, I966.

WELLS, W. D., GRUBER, G. The Life Cycle Concept in Marketing Research. Journal of Marketing Research, p.355-363, nov. I966.

WHEELWRIGHT, Steven C. Strategy, Manegement and Strategic Planning Approaches. Interfaces, v.14, p.19-36, jan./feb. I984. 